\title{
Analisa Gerakan Dermaga Apung dengan Menggunakan Software Moses (Studi Kasus: Pasca Gempa Di Gili Trawangan)
}

\author{
Asep Irwan ${ }^{1}$ \\ Teknik Sipil, Fakultas Teknik dan Desain, ITSB, Kabupaten Bekasi, Indonesia
}

\begin{abstract}
Abstrak
Bangunan terapung saat ini sudah banyak digunakan baik untuk kegiatan transportasi ataupun sarana penunjang lainnya. Salah satunya dermaga pontoon yang digunakan sebagai sarana tambat kapal baik di laut maupun di danau. Selain memberikan dampak positif bangunan ini juga sangat efektif dan efisien hal ini dikarenakan mudah dibuat, tidak memakan waktu lama serta ramah lingkungan dibandingkan jenis dermaga pada umumnya. Metode penelitian yang dilakukan dengan menggambil studi kasus di daerah perairan Gili Trawangan, di mana untuk simulasi menggunakan perangkat lunak MOSES. Batasan penelitian terfokus pada pengaruh gelombang yang akan dikaji dalam studi karakteristik gerakan pontoon yaitu dari arah pembebanan $0^{\circ}$, $45^{\circ}$, dan $90^{\circ}$ kemudian pemodelan pile diasumsikan menggunakan sistem mooring. Berdasarkan kriteria batas operasional, maka dari hasil analisa gerakan pontoon untuk arah pembebanan $0^{\circ}, 45^{\circ}$, dan $90^{\circ}$ didapat nilai maksimum Gerakan Heave (arah sumbu-z) sebesar $0.609 \mathrm{~m}$ dan batas kriteria yang diizinkan yaitu sebesar $1.96 \mathrm{~m}$ sehingga masih memenuhi. Maka pontoon tersebut dapat digunakan sebagai dermaga apung karena mempunyai nilai Gerakan Heave (arah sumbu-z) di bawah kriteria batas operasional, sehingga aman untuk dijalankan.
\end{abstract}

Kata-kunci: heave, software moses, mooring, pontoon.

\section{PENDAhUluan}

Fasilitas sarana tambat kapal menjadi hal terpenting untuk mendukung keberlangsungan transportasi air salah satunya dermaga. Transportasi air untuk lokasi di laut sangat kompleks dibandingkan dengan transportasi air di sungai, danau atau lainnya. Hal ini dikarenakan pengaruh lingkungan yang cukup kuat, sehingga penyelesaiannya berbeda. Saat ini pembangunan dermaga mengalami kemajuan seiring perkembangan ilmu dan teknologi. Pemilihan tipe dermaga sangat dipengaruhi oleh kebutuhan yang akan dilayani, ukuran kapal, arah gelombang, arus, angin, kondisi topografi dan kondisi tanah serta tinjauan ekonomi untuk mendapatkan bangunan yang paling ekonomis. Dermaga apung atau dermaga pontoon memiliki kelebihan tersendiri yaitu sangat efektif dan efisien. Hal 
ini dikarenakan mudah dibuat, tidak memakan waktu lama serta ramah lingkungan dibandingkan jenis dermaga pada umumnya. Penelitian ini berfokus pada analisis gerakan pontoon sebagai dermaga apung pada proses keluar-masuknya angkutan maupun penumpang dan lainnya. Studi kasus penelitian mengambil di Gili Terawangan pasca Gempa Lombok. Tujuan utamanya adalah untuk mengetahui apakah gerakan pontoon tersebut aman untuk dilalui atau tidak dengan menggunakan perangkat lunak MOSES (Multi-Operational Structural Engineering Simulator).

\subsection{Batasan Penelitian}

Batasan dan asumsi yang digunakan dalam pemodelan adalah sebagai berikut:

1. Pengaruh gelombang yang akan dikaji dalam studi karakteristik gerakan dermaga apung ini adalah dari arah $0^{\circ}, 45^{\circ}$, dan $90^{\circ}$.

2. Prediksi gerakan di gelombang reguler dilakukan dengan menerapkan teori difraksi 3-dimensi.

3. Perhitungan Response Amplitude Operator (RAO) mengacu pada metode 3-D atau metode Panel serta teori difraksi yang semuanya diakomodasi oleh perangkat lunak MOSES (Multi Operational Structural Engineering Simulator).

4. Analisis operabilitas akan dilakukan dengan mengacu pada hasil prediksi gerakan di gelombang acak dan mengkorelasikannya dengan kriteria yang sesuai.

5. Tidak melakukan analisa tegangan mooring.

\subsection{Kriteria Seakeeping}

Komponen atau sistem yang terkait di atas anjungan juga mempunyai batasan-batasan tertentu. Peralatan dan permesinan, yang mengandalkan kinerjanya dengan mengambil suplai bahan bakar atau fluida pelumas, tentu saja akan dipengaruhi oleh gerakan anjungannya. Semakin besar anjungan bergerak akan semakin besar pula gangguan pada pergerakan atau mengalirnya fluida menuju ke mesin. Hal ini tentunya akan membatasi sampai seberapa besar intensitas gerakan anjungan yang boleh terjadi di mana mesin masih dapat bekerja dengan lancar. Sebagai contoh lain adalah pemindahan muatan antar anjungan atau kapal. Pengoperasian transfer barang atau muatan tentu saja akan dibatasi oleh gerakan keduanya. Semakin besar gerakan maka akan semakin sulit aktivitas transfer dilakukan dan pada tahap yang lebih kritis akan memungkinkan terjadi kecelakaan. Penelitian kriteria seakeeping telah banyak dilakukan oleh US Navy, 1978, yaitu sebagai berikut:

1. Amplitudo gerakan roll rata-rata sebesar $12^{\circ}$.

2. Amplitudo gerakan pith rata-rata sebesar $3^{\circ}$.

3. Percepatan Heave Signifikan $<0.2 \mathrm{~g}\left(1.96 \mathrm{~m} / \mathrm{det}^{2}\right)$. 


\section{METODE}

Metode yang digunakan dalam penelitian ini adalah menggunakan teori gerakan bangunan apung. Dengan memakai konversi sumbu tangan kanan tiga gerakan translasi

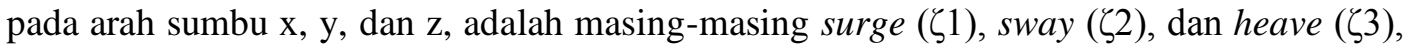

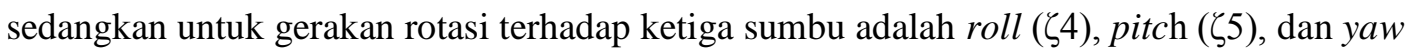

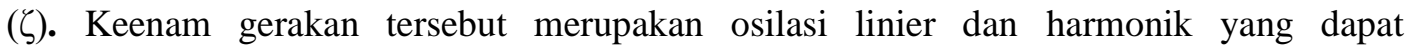
dinyatakan dalam persamaan diferensial gerakan kopel, dapat dituliskan sebagai berikut:

$$
\sum_{n=1}^{6}\left[\left(\mathbf{M}_{j k}+\mathbf{A}_{j k}\right) \zeta_{k}^{\&}+\mathbf{B}_{j k} \zeta_{k}^{\&}+\mathbf{K}_{j k} \zeta_{k}\right]=\mathbf{F}_{j} e^{i \omega t} \quad ; \quad j, k=1 \ldots \ldots 6
$$

\section{Di mana:}

Mjk = matriks massa dan momen inersia massa bangunan laut,

Ajk = matriks koefisien-koefisien massa tambah hidrodinamik,

Bjk = matriks koefisien-koefisien redaman hidrodinamik,

$\mathrm{Kjk} \quad=$ matriks koefisien-koefisien kekakuan atau gaya dan momen hidrostatik,

$\mathrm{Fj} \quad=$ matriks gaya eksitasi $(F 1, F 2, F 3)$ dan momen eksitasi $(F 4, F 5, F 6)$ dalam fungsi kompleks (dinyatakan oleh $\mathrm{e}^{\mathrm{iwt}}$ ),

F1 = gaya eksitasi yang menyebabkan gerakan surge,

F2 = gaya eksitasi yang menyebabkan gerakan sway,

F3 = gaya eksitasi yang menyebabkan gerakan heave,

F4 = momen eksitasi yang menyebabkan gerakan roll,

F5 = momen eksitasi yang menyebabkan gerakan pitch,

F6 = momen eksitasi yang menyebabkan gerakan yaw,

$\zeta_{k} \quad=$ elevasi gerakan pada mode $\mathrm{ke} \mathrm{k}$,

$\sum_{k}^{\&}=$ elevasi kecepatan gerak pada mode ke $\mathrm{k}$,

$\stackrel{s}{k}=$ elevasi percepatan gerak pada mode $\mathrm{ke} \mathrm{k}$.

\subsection{Response Amplitude Operators (RAO)}

Hasil prediksi gerakan bangunan apung umum diberikan dalam bentuk perbandingan antara amplitudo mode gerakan tertentu dengan amplitudo gelombang insiden, yang berfungsi sebagai fungsi perubahan frekuensi gelombangnya. Perbandingan amplitudo tersebut adalah disebut sebagai Response Amplitude Operator (RAO). RAO atau disebut juga dengan transfer function merupakan fungsi respons gerakan dinamis suatu benda apung yang disebabkan oleh gelombang dengan rentang frekuensi tertentu. RAO merupakan alat untuk mentransfer gaya gelombang menjadi respon gerakan dinamis struktur. Menurut Chakrabarti (1987), persamaan RAO dapat dicari dengan rumus sebagai berikut:

$$
R A O(\omega)=\frac{X_{p}(\omega)}{\eta(\omega)}
$$


Di mana:

$$
\begin{aligned}
& X_{p}(\omega)=\text { Amplitudo struktur apung } \\
& \eta(\omega)=\text { Amplitudo gelombang }
\end{aligned}
$$

Syarat pemilihan teori untuk perhitungan gaya gelombang didasarkan pada perbandingan antara diameter struktur (D) atau panjang struktur dengan panjang gelombang $(\lambda)$ sebagai berikut:

$\mathrm{D} / \lambda>1=$ gelombang mendekati pemantulan murni, persamaan morison tidak valid.

$\mathrm{D} / \lambda>0,2=$ difraksi gelombang perlu diperhitungkan, persamaan morison tidak valid $\mathrm{D} / \lambda<0,2=$ persamaan morison valid.

\subsection{Kriteria Desain}

Pada penelitian ini digunakan data utama untuk Dermaga Apung dan Kapal Penumpang yaitu sebagai berikut:
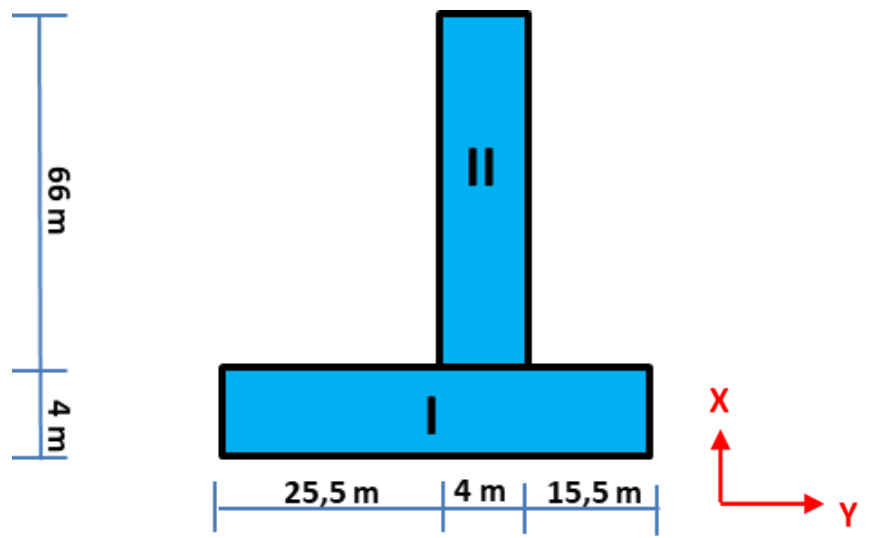

Gambar 1. Desain dermaga apung

Tabel 1. Dimensi utama kapal

\begin{tabular}{ccc}
\hline Deskripsi & Unit & Nilai \\
\hline Panjang Kapal (L) & $\mathrm{m}$ & 12 \\
Lebar (B) & $\mathrm{m}$ & 3 \\
Tinggi (H) & $\mathrm{m}$ & 1,3 \\
Draft (T) & $\mathrm{m}$ & 0,5 \\
Kapasitas Penumpang & Person & 20 \\
\hline
\end{tabular}

Sumber data: hasil survey, 2018 
Berikut adalah data lingkungan yang digunakan dalam analisis:

\begin{tabular}{ccc}
\multicolumn{4}{c}{ Tabel 2. Data lingkungan } \\
\hline Deskripsi & Unit & Nilai \\
\hline Kedalaman Perairan & $\mathrm{M}$ & 3.00 \\
Tinggi Gelombang & $\mathrm{M}$ & 1.18 \\
Periode Gelombang & $\mathrm{S}$ & 4.70 \\
Kecepatan Arus & $\mathrm{m} / \mathrm{s}$ & 0.36 \\
\hline Sumber Data : Hasil Survey, 2018
\end{tabular}

Arah pembebanan lingkungan yang mengenai struktur dermaga apung dapat dilihat pada gambar berikut ini.

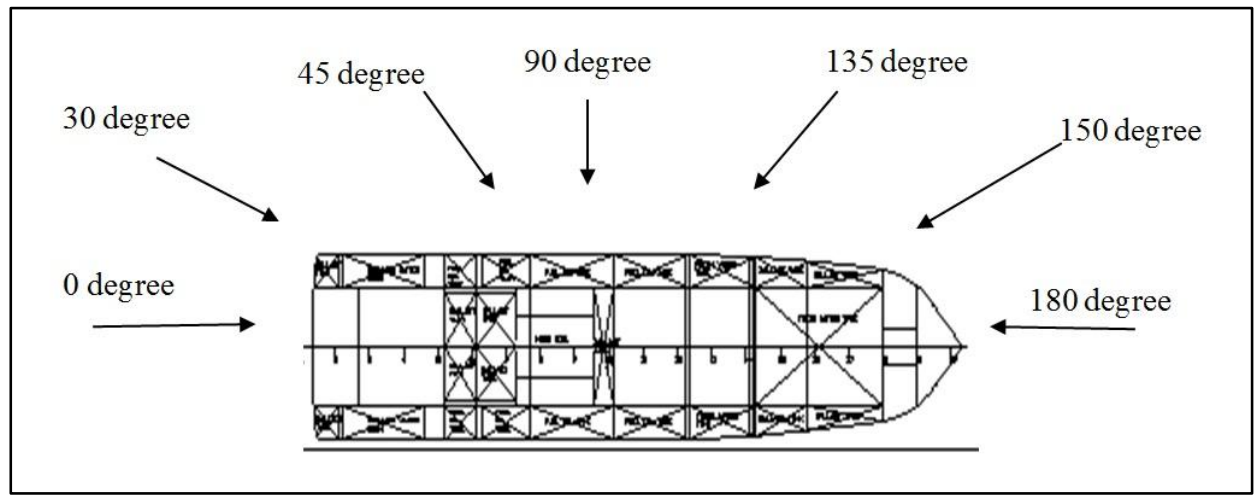

Gambar 2. Arah pembebanan lingkungan pada struktur apung

\section{PEMBAHASAN DAN DISKUSI}

Pada dasarnya pengaruh muatan terhadap perilaku gerak Dermaga Apung adalah berubahnya titik pusat gravitasi Dermaga Apung akibat penambahan muatan dan juga peletakannya di atas Dermaga Apung tersebut, sehingga perilaku gerak Dermaga Apung pun berubah. Pada studi ini, diasumsikan beban yang diterima dermaga sekitar $360 \mathrm{~kg} / \mathrm{m}^{2}$. Adapun perhitungan titik berat yang diterima dermaga apung adalah sebagai berikut.

Tabel 3. Perhitungan titik berat dermaga apung

\begin{tabular}{ccccccccc}
\hline No. & Deskripsi & $\begin{array}{c}\mathrm{W} \\
\text { (ton) }\end{array}$ & $\begin{array}{c}\mathrm{X} \\
(\mathrm{m})\end{array}$ & $\begin{array}{c}\mathrm{Y} \\
(\mathrm{m})\end{array}$ & $\begin{array}{c}\mathrm{Z} \\
(\mathrm{m})\end{array}$ & $\begin{array}{c}\mathrm{W}^{* \mathrm{X}} \\
\text { (ton.m) }\end{array}$ & $\begin{array}{c}\mathrm{W}^{*} \mathrm{Y} \\
\text { (ton.m) }\end{array}$ & $\begin{array}{c}\mathrm{W}^{* \mathrm{Z}} \\
\text { (ton.m) }\end{array}$ \\
\hline 1 & Dermaga 1 & 1008 & 2 & 0 & 0,4 & 2016 & 0 & 403,2 \\
2 & Dermaga 2 & 1478,4 & 37 & 5,5 & 0,4 & 54700,8 & 8131,2 & 591,36 \\
\hline & Jumlah & 2486,4 & & & & 56716,8 & 8131,2 & 994,56 \\
\hline
\end{tabular}

Dari tabel di atas maka didapat titik berat dermaga tersebut yaitu, $\mathrm{Xo}=3,3 \mathrm{~m}, \mathrm{Yo}_{\mathrm{o}}=22,8 \mathrm{~m}$, $\mathrm{Zo}=0,4 \mathrm{~m}$.

\subsection{Perilaku Gerakan Dermaga Apung Untuk Arah Pembebanan Lingkungan $0^{\circ}$}

Hasil komputasi respon gerakan pada Pontoon di atas gelombang reguler pada kondisi stasioner untuk arah pembebanan $0^{\circ}$, telah disusun dalam bentuk kurva-kurva RAO seperti yang disajikan pada gambar di bawah ini untuk enam mode gerakan pada model. Sehubungan dengan variasi frekuensi, komputasi telah dilakukan mulai dari frekuensi 
gelombang insiden $\omega=0.2513 \mathrm{rad} / \mathrm{sec}$ sampai dengan $2.0944 \mathrm{rad} / \mathrm{sec}$. Atau bila ditinjau dari periode gelombang, sebagai kebalikannya adalah mulai dari tiga detik sampai dengan sekitar 25 detik. Gambar berikut ini merupakan Kurva RAO untuk arah pembebanan $0^{\circ}$.

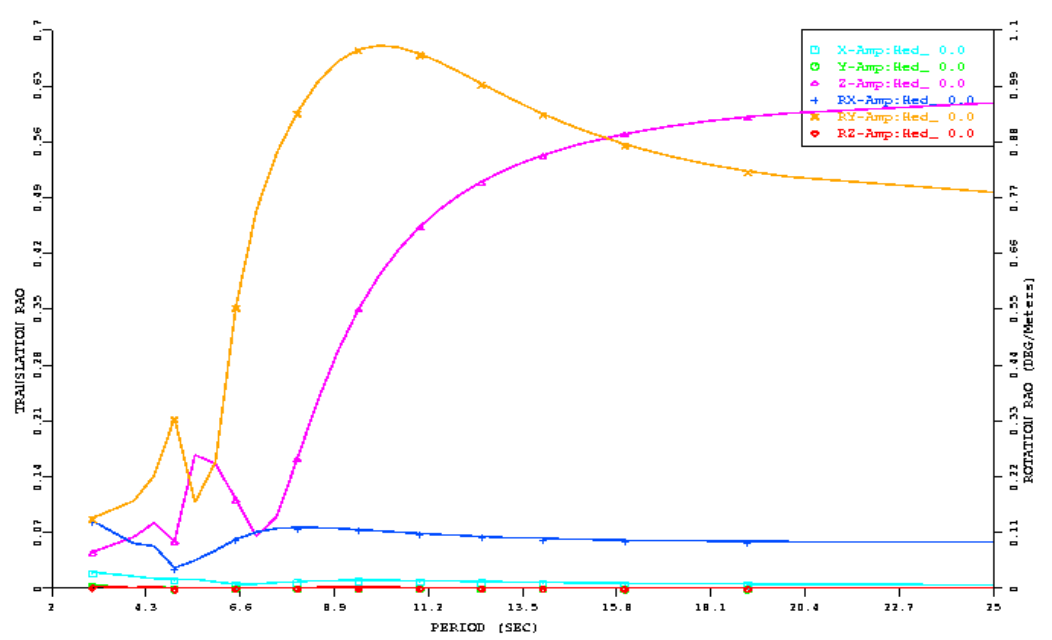

Gambar 3. RAO dermaga arah pembebanan $0^{\circ}$

\subsection{Perilaku Gerakan Dermaga Apung Untuk Arah Pembebanan Lingkungan $4^{\circ}$}

Hasil komputasi respon gerakan pada pontoon di atas gelombang reguler pada kondisi stasioner untuk arah pembebanan $45^{\circ}$, telah disusun dalam bentuk kurva-kurva RAO seperti yang disajikan pada gambar di bawah ini untuk enam mode gerakan pada model. Sehubungan dengan variasi frekuensi, komputasi telah dilakukan mulai dari frekuensi gelombang insiden $\omega=0.2513 \mathrm{rad} / \mathrm{sec}$ sampai dengan $2.0944 \mathrm{rad} / \mathrm{sec}$. Atau bila ditinjau dari periode gelombang, sebagai kebalikannya adalah mulai dari tiga detik sampai dengan sekitar 25 detik. Gambar berikut ini merupakan Kurva RAO untuk arah pembebanan $45^{\circ}$.

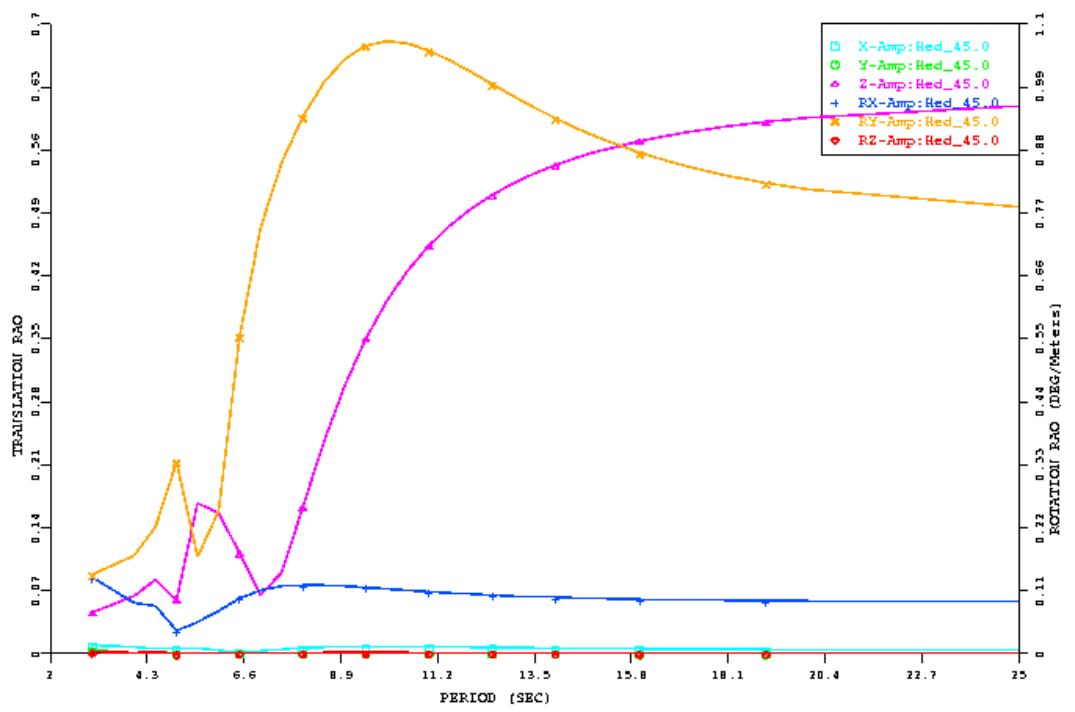

Gambar 4. RAO dermaga arah pembebanan $45^{\circ}$ 


\subsection{Perilaku Gerakan Dermaga Apung Untuk Arah Pembebanan Lingkungan $90^{\circ}$}

Hasil komputasi respon gerakan pada pontoon di atas gelombang reguler pada kondisi stasioner untuk arah pembebanan $90^{\circ}$, telah disusun dalam bentuk kurva-kurva RAO seperti yang disajikan pada gambar di bawah ini untuk enam mode gerakan pada model. Sehubungan dengan variasi frekuensi, komputasi telah dilakukan mulai dari frekuensi gelombang insiden $\omega=0.2513 \mathrm{rad} / \mathrm{sec}$ sampai dengan $2.0944 \mathrm{rad} / \mathrm{sec}$. Atau bila ditinjau dari periode gelombang, sebagai kebalikannya adalah mulai dari tiga detik sampai dengan sekitar 25 detik. Gambar berikut ini merupakan Kurva RAO untuk arah pembebanan $90^{\circ}$.

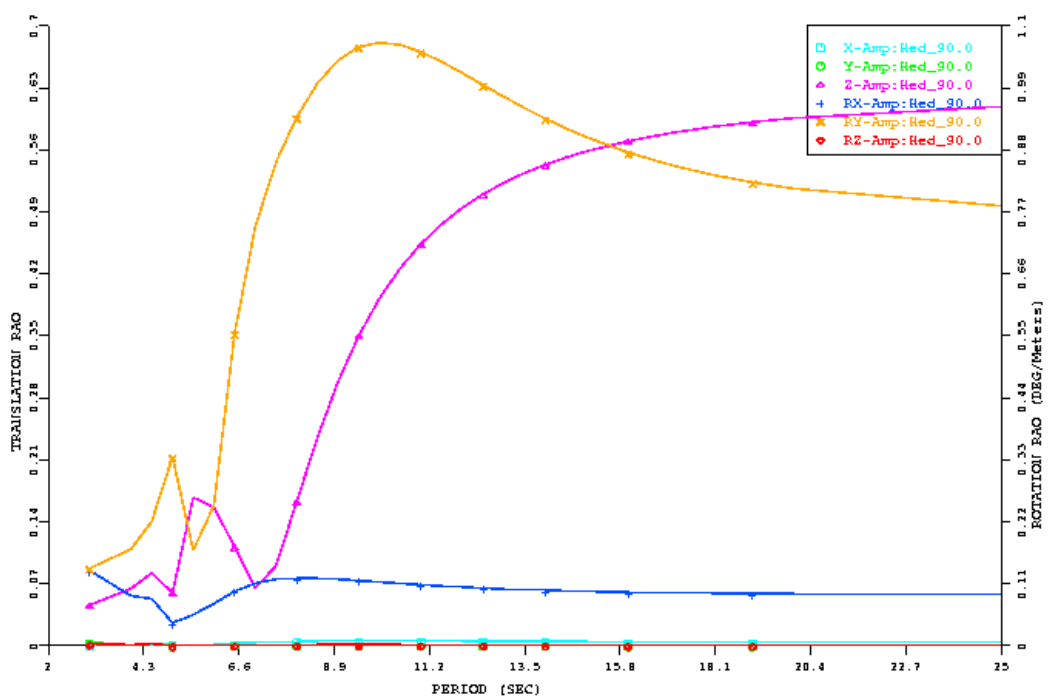

Gambar 5. RAO dermaga arah pembebanan $90^{\circ}$

Dari hasil analisa gerakan Dermaga Apung untuk arah pembebanan $0^{\circ}, 45^{\circ}$, dan $90^{\circ}$ di atas, didapat nilai maksimum dari masing-masing gerakan yaitu:

Tabel 4. Nilai RAO maksimum

\begin{tabular}{cccccc}
\hline $\begin{array}{c}\text { Surge } \\
(\mathrm{X})\end{array}$ & $\begin{array}{c}\text { Sway } \\
(\mathrm{Y})\end{array}$ & $\begin{array}{c}\text { Heave } \\
(\mathrm{Z})\end{array}$ & $\begin{array}{c}\text { Roll } \\
(\mathrm{RX})\end{array}$ & $\begin{array}{c}\text { Pitch } \\
(\mathrm{RY})\end{array}$ & $\begin{array}{c}\text { Yaw } \\
(\mathrm{RZ})\end{array}$ \\
\hline$(\mathrm{m} / \mathrm{m})$ & $(\mathrm{m} / \mathrm{m})$ & $(\mathrm{m} / \mathrm{m})$ & $(\mathrm{deg} / \mathrm{m})$ & $(\mathrm{deg} / \mathrm{m})$ & $(\mathrm{deg} / \mathrm{m})$ \\
0.005 & 0.020 & 0.609 & 1.071 & 0.133 & 0.004 \\
\hline
\end{tabular}




\section{KESIMPULAN}

Berdasarkan kriteria batas operasional, maka dari hasil analisa gerakan Dermaga Apung untuk arah pembebanan $0^{\circ}, 45^{\circ}$, dan $90^{\circ}$ masih di bawah nilai batas kriteria yang diizinkan yaitu untuk gerakan heave (Z) hasil perhitungan $0.609 \mathrm{~m}<1.96 \mathrm{~m}$ (batas maksimum), gerakan roll (RX) hasil perhitungan $1.071 \mathrm{deg} / \mathrm{m}<12 \mathrm{deg} / \mathrm{m}$ (batas maksimum) dan untuk gerakan Pitch (RY) hasil perhitungan $0.133 \mathrm{deg} / \mathrm{m}<3 \mathrm{deg} / \mathrm{m}$ (batas maksimum). Maka desain Dermaga Apung tersebut dapat digunakan karena mempunyai nilai gerakan enam derajat kebebasan di bawah kriteria batas operasional sehingga aman untuk dijalankan.

\section{UCAPAN TERIMA KASIH}

Penulis mengucapkan terima kasih kepada semua pihak yang sudah membantu dalam kelancaran penelitian yang dilakukan.

\section{DAFTAR PUSTAKA}

1) Chakrabarti, S.K., 1987. Hydrodynamics of Offshore Structure. Berlin: SpringerVerlag.

2) Olson, S.R., An Evaluation of the Seakeeping Qualities of Naval Combatants, Naval Engineering Journal, ASNE, Vol. 90, No.1, pp. 23- 40 (1978).

3) Reference Manual For Moses. Bentley Sustaining Infrastucture, Inc. June, 1989 and October 7, 2013. 